\title{
THE CONCEPT OF THE STIMULUS IN PSYCHOLOGY ${ }^{1}$
}

\author{
JAMES J. GIBSON
}

Cornell University

$\mathrm{I}$ T seems to me that there is a weak link in the chain of reasoning by which we explain experience and behavior, namely, our concept of the stimulus. The aim of this paper is to find out what psychologists mean by the term stimulus, with the hope of deciding what they ought to mean by it. After a short look at the history of the term, I will try to uncover the sources of confusion in modern usage. In the end, perhaps, the concept will be clarified. If not, certain contradictions will have been brought to light.

The experimental study of the stimulus began in the eighteenth century, so far as I can tell, with an investigation of the curious things that could be done to make a frog's leg twitch. The experimenters discovered what is now called the nerve-muscle preparation. Galvani and later Volta gave their names to electricity as well as to physiology by their experiments. In the early nineteenth century Johannes Müller applied these discoveries to the philosophers' problem of the human senses, the gates of knowledge. The nerves of sense, he pointed out, can be excited by a variety of unnatural agencies such as electrical current. Since the mind is acquainted only with the qualities specific to the sensory nerves, not with the stimuli, how it gets knowledge of the material world became more puzzling than ever. Later in the century, Sherrington was to emphasize the extent to which receptors are naturally protected against such irrelevant stimuli by the structural specialization of sense organs. But meanwhile it had been discovered that the skin would yield sensations only at certain discrete points. Here was a fresh puzzle. The separate receptor cells of all the sense organs came to be seen under the microscope, and the punctate character of the sensory process seemed to be established.

During all this time, the physical scientists were discovering the laws of energy and triumphantly measuring it in its various forms, electricity, momentum, light, heat, sound, and the results of chemical reaction. It became possible to measure certain

\footnotetext{
1 Presidential Address to the Eastern Psychological Association, New York, New York, April 1960.
}

variables of energy at sense organs, at least the simple ones like frequency and amount. Thresholds of reportable sensation were established. Fechner, following Weber, conceived the grand scheme of a measurement formula for consciousness, relating its judged intensity to a simple variable of the stimulus. Psychophysics was born.

Whatever could be controlled by an experimenter and applied to an observer could be thought of as a stimulus. In the growing science of human psychology, it became evident that this was the independent variable of an experiment, to be isolated and systematically varied. Much more complex things than physical energies could be presented to the sense organs-words for instance. These were also called stimuli, although the stimulus conditions manipulated, recency, frequency, meaningfulness, were vastly different from the variables of the psychophysical experiment.

In the latter part of the nineteenth century the concept of the reflex arc was applied to the adaptive behavior of animals. It had been thought to explain the strictly mechanical actions of the body ever since Descartes. Reflexes had stimuli. The situations of animals could be systematically altered and the reactions observed. Organisms obviously responded to such stimuli, and the experimenter could apply them more freely than he could venture to do with human beings. To shorten a long story, such experiments came to be merged with human experiments and the outcome was a general stimulus-response psychology. This was a great success, especially in America. But stimuli for animal psychologists were not the same as stimuli for sensory physiologists and stimuli were still different for the students of perception and learning.

Enough has been said to show that in the twentieth century we have inherited a mixed batch of ideas about the stimulus. We constantly use the word but seldom define it. We take it for granted. We have behavior theory in full bloom, and perception theory in ripened complexity, but who ever heard of stimulus theory? As a preliminary effort in this direction, I have made a survey of what 
modern writers seem to mean by the term. Some writers define it, but not many. My method was to collect quotations from books. I then put them in opposition to one another. The ways of conceiving the stimulus are often in flat contradiction. Occasionally one book can be quoted against itself. The issues interlock, of course, but I have separated them into eight areas of disagreement and will treat them separately. In what follows, I will quote without comment, for the most part, keeping my own opinions to the end.

1. For Freud, the only use of the term stimulus that is discoverable in the Collected Papers (1949) is to refer to a motivating force. This, after all, is the dictionary meaning of the word-something that arouses or impels to action. In ordinary speech we refer to the stimulus of hunger or fear, which may compel extreme forms of behavior. Freud does not often use the term, but when he does, a stimulus is something to be satisfied or warded off.

Psychologists and physiologists, however, have generally used the term for the arousing of a sense organ instead of a whole individual. But they do not wholly agree about this. Some accept both meanings. Neal Miller asserts that "any stimulus has some drive value" (Miller \& Dollard, 1941, p. 59). However, Skinner believes that "a drive is not a stimulus," and that although "the term has the unfortunate connotation of a goal or spur to action," we must not be misled by this popular meaning of the word $(1938$, p. 375). Here, then, is a first area of disagreement in our way of conceiving the stimulus: does a stimulus motivate the individual or does it merely trigger a response?

I1. Pavlov said that "a stimulus appears to be connected with a given response as cause with effect" $(1927$, p. 10). This is a forthright assertion. Similarly Watson took as the whole aim of psychology the predicting of the response, given the stimulus, and the specifying of the stimulus, given the response $(1924$, p. 10). But contrast this with the caution of Hilgard and Marquis. "We refer to a stimulus as an instigator [and] no more is intended than that the stimulus is in some sense the occasion for the response" (1940, p. 73). Evidently what Pavlov and Watson meant by a stimulus is not what Hilgard and Marquis meant. Nearly all psychologists now follow the second line. It is allowed that a stimulus may cause a reflex, but not an act.
Woodworth was one of the first to emphasize that the stimulus does not in itself determine the response; factors in the organism intervene to help determine it. The discussion of intervening variables or mediating processes has by now filled volumes.

The same rule is taken to hold for experience. It is allowed that a stimulus may cause a sensation, but not a perception. M. D. Vernon, for example, states that "the nature of the percept is not ... determined by the physical qualities of the stimulus, but is largely a function of constructive tendencies in the individual" $(1952$, p. 47$)$. But I have been arguing the opposite for some time, that the percept is in very good correspondence with the physical variables of the stimulus. Can a stimulus be taken as the sufficient cause of a response, or can it not? This is a second area of confusion in our concept of the stimulus.

III. Skinner has recently noted that "we frequently define the stimulus by the very doubtful property of its ability to elicit the response in question, rather than by any independent property of the stimulus itself" (1959, p. 355). He suggests no remedy, however, for this doubtful scientific behavior, and he seems to be confessing a sin without pointing the way to salvation. In truth many psychologists do give a circular definition of the stimulus. Skinner himself believed in his first book that "neither term [stimulus or response] can be defined as to its essential properties without the other" (1938, p. 9). Neal Miller has said "a response is any activity by or within the individual which can become functionally connected with an antecedent event through learning; a stimulus is any event to which a response can become so connected" (Miller \& Dollard, 1941, p. 59). Miller, in fact, has argued that this circular definition of the stimulus is not only necessary but is theoretically desirable (Koch, 1959 , p. 239). He seems to have abandoned completely the specifying of a stimulus by variables of physical energy. But listen to Estes. "By stimulus, I refer to environmental conditions, describable in physical terms without reference to the behavior of an organism" (Koch, 1959, p. 455), and Hayek says, "the distinction between different stimuli must be independent of the different effects they have on the organism" $(1952$, p. 9).

Here is a disagreement. The student of psychophysics will argue that we must define our stimulus 
by certain operations of physical science, not by the judgments of our subject. Otherwise how are we ever to discover what stimuli can be discriminated and what cannot? When the stimulus is difficult to specify in objective physical terms, however, investigators tend to avoid the difficulty and describe it as that which is responded to, or that which is perceived. A few go further and, by arguing that an experimenter cannot define the stimulus anyway except in terms of his perception, reach a philosophical position of subjectivism. There is an ancient puzzle to which students of philosophy are treated -whether there exists any sound when a tree crashes in the forest with no living being there to hear it. It is a question of how to conceive the auditory stimulus. It seems to remain a puzzle for a good many psychologists.

I think the central question is the following. Is a stimulus that which does activate a sense organ or that which can activate a sense organ? Some writers imply that a stimulus not currently exciting receptors is not a stimulus at all. Others imply that a stimulus need not excite receptors to be called such. They allow of potential stimuli. Witness Guthrie's assertion that stimuli are "potential occasions" for the initiation of sensory activity, and that "the physical stimuli, though present, may not be effective" (Koch, 1959, p. 178). The former conception allows physical energy to be called a stimulus only when some response can be observed; the latter allows of the possibility that stimulus energy may be present without necessarily being responded to. The latter seems the better concept. With the former meaning, one could never speak of a subthreshold stimulus, and this is a useful term. An effective stimulus on one occasion may be ineffective on another. And there are various response criteria by which a threshold can be measured.

The distinction between effective and potential stimuli is made by a few theorists, but its implications have not been traced, and the idea remains undeveloped. The concept of a permanent environment of objects is widely accepted, but not the concept of a permanent environment of potential stimuli.

The third area of disagreement is this: must a stimulus be defined independently of the response it produces-in physical terms rather than terms of behavior or sensory process?
$I V$. For Pavlov a stimulus could be anything in the terrestrial world. Any event he could think of to use in an experiment he would call a stimulus, and he employed tones, bells, the sound of bubbling water, lights, rotating objects, pictures on a screen, acid in the mouth, food, a scratch on the back, or electric shock. This common sense usage of the term persists among a good many behaviorists. Spence has said that the term stimulus means to him, "the physical or world situation, with its different aspects or features" (1956, p. 39). For Neal Miller anything that is discriminable is a stimulus or, as he calls it, a cue, these terms having the same meaning. For Skinner, a stimulus is simply "a part, or modification of a part, of the environment" (1938, p. 235). To be sure, he says, it must "refer to a class of events the members of which possess some property in common" (p. 34). Because stimuli have this "generic nature," the practice of calling a bell an auditory stimulus and a book a visual stimulus is, as he puts it, "frequently successful" (p. 235). All these writers persist in believing that somehow the things of the environment can stimulate us, and they refuse to be worried by the paradox that only receptors at the skin of an individual can actually be stimulated.

This definition of the stimulus is considered naive by perception psychologists. Stimuli are energies, not objects. In Troland's words, "the stimulus may be defined as the specific physical force, energy, or agency which brings about the stimulation of the given receptor system" (1930, p. 9). This conception has the authority of a century's research on the senses. In 1834, Johannes Müller argued that a stimulus was whatever excited one of the "nerves of sense." To the modern neurophysiologist, a stimulus is energy that depolarizes a living cellespecially, but not exclusively, a nerve cell. For Jennings in 1906, studying the ameba, a stimulus was a type of change in the immediate environment that produced a change in behavior (1906, p. 19) and there existed precisely five types: chemical, mechanical, thermal, photic, or electrical. Woodworth says that "a stimulus is any form of energy acting upon a sense organ and arousing some activity of the organism" $(1929$, p. 223$)$. Koffka wishes to call stimuli "the causes of the excitations of our sense organs" (1935, p. 79), but he, more than any other theorist, faced up to the contradictory meanings of the term and proposed a formal distinction between the "proximal" stimulus and the "distal" 
or "distant" stimulus. He made us consider the paradox that although perception and behavior seem to be determined by the distal object, they can in fact only be aroused by the proximal stimulus.

Not all psychologists are willing to grapple with this paradox and, in truth, it is baffling. If the proximal stimulus for a given object is altered with every change of the observer's position in space, if it is different on different occasions, we are faced with an absurdity. We must suppose that a countless family of different stimuli can all arouse the same percept. Most behaviorists speak of the stimulus-object as if, by hyphenating two words with different meanings, the absurdity were removed. As men of common sense they see the need of reducing to one the countless number of stimuli that can arouse a single percept, and in this surely they have a point. But perceptionists, being unable to take this easy way out, struggle to construct theories of how different stimuli might arouse the same percept, the theories of perceptual constancy. So far, no theory has been agreed on. Is it possible that common sense is right without knowing it, and that every family of proximal stimuli arising from one object $i s$, in a sense, one stimulus?

Here is a fourth disagreement: do stimuli exist in the environment or only at receptors? There is a suggestion that both usages of the term are somehow correct, but it has not been explained.

$V$. Osgood says that "a stimulus may be defined as that form of physical energy that activates a receptor" (1953, p. 12). But he does not tell us whether he means by a receptor a single cell or a mosaic of receptor cells, that is, a sense organ. Others besides Osgood are undecided about this question, or have not thought about it. Hull knew what he thought. For him, the retinal image was a pattern of stimuli (1943, p. 37) and a single light ray was a stimulus (p. 33). "A stimulus element is a stimulus energy which activates a single receptororgan" (p. 349). This is straightforward. Woodworth says that "of course the light entering the eye and striking many rods and cones is a collection of stimuli rather than a single stimulus," but in the next paragraph he suggests that "the sudden cessation of a light" is a stimulus (1929, p. 28). Köhler was fairly explicit on the question, saying that an organism responds to "an objective constellation of millions of stimulj" (1929, p. 179) and Koffka also assumed that stimuli on the retina or the skin were local events (1935). But Nissen, on the other hand, asserts that "a stimulus involves a pattern of stimulation, spatial or temporal" (Stevens, 1951, p. 374). Many other writers define stimuli as the occasions for activation of a sense organ, not of a receptor cell, and speak as if a pattern were a stimulus. There is a vast difference between a pattern of stimuli and a stimulus pattern, but we have not sufficiently thought about it. Is a "pattern" a single stimulus or is it a number of separate stimuli?

The notion that a stimulus is what excites a cell, and is therefore punctate, seems to many theorists the only rigorous definition. On this account Hull had to introduce the postulate of afferent neural interaction to explain molar behavior as distinguished from molecular responses. The gestalt psychologists had to develop the theory of sensory organization in order to explain perception. But Lashley once said that

the stimulus to any reaction above the level of a spinal reflex involves not the excitation of certain definite sensory cells but the excitation of any cells of a system in certain ratios, and the response may be given to the ratio even though the particular cells involved have not previously been excited in the same way (Murchison, 1934, p. 476).

This passage suggests the idea that higher levels of reaction require us to define higher orders of stimulation. Lashley seems to be saying that a ratio may be itself a stimulus, not just a relation between two stimuli. But note that the gestalt theorists, by conceiving all stimuli as local events, did not come to think in this way.

A controversy has long been going on over the question of how an individual could respond to a relation. It began with Köhler's evidence that a chick will select the brighter of two gray papers instead of the absolute brightness of a particular paper. Köhler thought it demonstrated a relational process in the brain; Spence has gone to great lengths to show that it could be explained in terms of absolute responses to each piece of paper, subject to the so-called principle of stimulus generalization. But the simplest explanation would be that the effective stimulus in the experiment was the direction of the difference in brightness in the field of view. In line with this solution to the problem, students of vision conceive that a margin is a visual stimulus, perhaps the visual stimulus, and a margin in the array of light to an eye is strictly a ratio, that is, a relation between measured intensities. 
Here is a fifth source of confusion: when is a pattern or relation to be considered a single stimulus and when a number of separate stimuli?

VI. The notion that a stimulus can only be something punctate is related to the notion that a stimulus can only be something momentary. The gestalt psychologists pointed out that a melody is perceived, but they never suggested that a melody was a stimulus. The notes of the melody were taken to be the stimuli. But what about the transitions between notes, or the "transients" of acoustical engineering? Are they stimuli? The investigators of speech sounds seem to think so, but the auditory literature of sensation is vague on this question. And if a short transition is a stimulus, why not a long transition or temporal pattern?

In vision, experimenters have not been able to make up their minds as to whether an optical motion was a stimulus or a series of stimuli. The retina and also the skin are very sensitive to motion. It ought to be simple, but the facts of the stroboscope and the phi-phenomenon have been interpreted to imply that it is complex. Motion is taken to be change of location, as it is in classical physics, and it is then reasoned that the impression of location must be fundamental to any perception of a change of location.

On the other hand the generalization is frequently met with that a stimulus is always a change. This is very confusing, in fact it is one confusion piled on another. I think that writers who make this assertion have in mind the experiments showing that an unchanging stimulus soon ceases to be effective for perception. They are thinking of sensory adaptation. What changes in that case is not the stimulus but the process of excitation. For the retina, the skin, and the olfactory organ, sensory adaptation does occur. For example, the steady application of an image to a human retina, by the method of artificially stabilizing the image, eventuates in a wholly ineffective stimulus. But note that the steady application of focusable light to a human eye does not. This stimulus never becomes wholly ineffective, even with the best voluntary fixation, because of slight movements of the eye itself. This means that retinal stimulation is by no means the same thing as optical stimulation. They are different stages in the chain of events that leads to vision. A "change in stimulation" means something quite different when it is produced by some adjustment of the sense organ itself than when it is produced by an external event.

Is optical motion, then, meaning a change in the pattern of focusable light to the eye, to be considered a stimulus? Experiments based on this assumption are beginning to appear. In the recent Cornell research with optical transformation (Gibson \& Gibson, 1957) we not only think of this as a stimulus, we have come to think of nonchange of pattern as simply a special case. Stability, after all, is only definable as absence of motion. Similarly, a form is definable as a nontransformation. In this conception, sequence is a dimension of stimulation whether or not change occurs.

The great virtue of this conception of sequence is that it suggests a simple solution to the puzzle of perceptual constancy. Two types of nonchange are distinguishable, first, nonmotion of a pattern and, second, invariance of a pattern during motion. The invariant contained in a family of the perspectives arising from a single object is a single stimulus. Hence there is only one stimulus for a single object, and the common sense opinion is right after all.

The sixth conceptual issue is this: when does $a$ sequence constitute a single and when a number of separate stimuli; also, can a single enduring stimulus exist throughout a changing sequence?

VII. Users of the Rorschach test assume that a stimulus field can be either structured or, as they put it, unstructured. I could find no explicit definition of unstructured stimulation in the literature but only examples of the material to which the term is applied-inkblots and other items used in the so-called projective tests. The idea of structured stimulation comes from gestalt theory but only from a vague, tentative, and undeveloped hypothesis of gestalt theory-the external forces of organization as distinguished from the internal forces of organization. Koffka, for example, was so preoccupied with the ways in which the individual structured his stimulus field that he scarcely considered the ways in which it might already have structure (1935). In fact, he wrote sometimes as if it had none, as if all structure had to be imposed on it, because the stimuli themselves were meaningless points.

This uncertainty about the existence of structure in the stimulus for perceived form still persists. But since Koffka's time, and partly inspired by him, some experimenters are beginning simply to 
assume it, and to apply mathematics to the structure of a stimulus. They would not agree that an inkblot is in any sense an unstructured stimulus. A picture has one structure, an inkblot has another, but it does not lack structure. That can be said only of a film-color or the cloudless blue sky. The structure of an array may have ambiguous or equivocal components, as Koffka showed, but that is not the same thing. The capacity of light to carry structure to an eye may be impoverished or reduced experimentally but it remains. The structure of light may not specify anything familiar to the subject, or to any observer, but it is a geometrical fact. The subject may be unable to register the structure because it is nonsense to him, or he overlooks it, or he was not told to look for it, or his eyes are defective, or he is too young, or for a dozen other reasons, but it is still in the light. So, at least, some experimenters would argue.

What can be meant by an unstructured stimulus field is thus a matter of disagreement. The seventh question is: how do we specify the structure of a stimulus?

VIII. The conception of stimuli as physical energies seems to imply that, in themselves, they have no significance or meaning. Especially if they are considered to be only spots of energy at brief moments of time it is clear that they specify little or nothing about the environment. Light, heat, mechanical, acoustical, chemical, and electrical energy are far from being objects, places, events, people, words, and symbols, but nevertheless they are the only stimuli that can affect receptors. This theory of the meaningless stimulus has been an accepted doctrine for a long, long time in the study of the senses. It leads to the notion of the sense datum-the bare sensation, or raw sensory impression, and thence to the persistent problem of how animals and men can be supposed to perceive objects, places, events, and one another.

Students of behavior, however, without questioning the doctrine of the empty stimulus, often act as if they did not believe it. Beach speaks for comparative psychologists when he says, in describing how birds feed their offspring, "young birds exhibit a gaping response which stimulates the parent to place food in the nestling's mouth" (Stevens, 1951, p. 415). He takes it for granted that light rays can specify the event called gaping and refuses to worry about it further. Students of perception do worry about this question, but they are not consistent. On the one hand, they firmly assert that nothing gets into the eye but light of variable wave length and intensity, not objects, or events, or facts of the environment. On the other hand, they often say that light "carries" information about the environment, or that stimuli "provide" information to the perceiver. If this is so, the stimuli must specify something beyond themselves, and they cannot be empty of meaning.

A sort of compromise between the informative stimulus and the empty stimulus is provided by the use of the term cue. According to Woodworth, "a cue, as used in psychology, is a stimulus which serves as a sign or signal of something else, the connection having previously been learned" (1958, p. $60)$. Stimuli are conceived by analogy with messages, or communication in code. Brunswik thought of stimuli as indicators of environmental facts, by analogy with pointer readings, emphasizing, however, that they had only a probable connection with the fact in question (1956). Boring has suggested that stimuli may be taken as clues, and this term points to Helmholtz's theory of unconscious rational inference from the sense data (Harper \& Boring, 1948).

Merely to call the stimulus a cue, sign, signal, message, indicator, or clue does not tell us what we need to know. The question is to what extent does the stimulus specify its source, and how does it do so? Is it possible that the use of these verbal metaphors only prevents us from facing the problem? Or consider the use by modern information theorists of a neutral term like input. When they compare the organism to a communication system or to a black box, the internal working of which has to be discovered, are they avoiding the obligation to consider the environment of an organism and the relation of stimuli to the environment?

The problem of the connection between stimuli and their natural sources has not been taken seriously by psychologists. Stimuli have not even been classified from this point of view, but only with respect to the sense organs and the types of energy which carry stimuli. It is a problem of ecology, as Brunswik realized when he wrote about the "ecological validity" of cues (1956). I think the problem has been obscured, and our recognition of it delayed, by our failure to separate it into parts. The connection between natural stimuli and their sources is not the same as the connection between 
social stimuli and their sources, for example, the connection between words and their referents. This latter problem, surely, is distinct. Semantics is one thing, ecology is another; and a science of environmental stimuli may not prove to be as difficult as a science of symbols, once we put our minds to it.

I have maintained that optical stimuli, for example, gradients of texture in the light to an eye, specify environmental objects by the relation of projection. To me this is not at all the same as the relation by which words specify objects, which I would call one of coding. But however this may be, we face another unanswered question, the eighth: do stimuli carry information about their sources in the world, and how do they specify them?

\section{Some Positive Hypotheses}

Can anything useful be salvaged from these various contradictory usages and definitions? No one could be blamed for being pessimistic about it. S. S. Stevens, who has thought hard and long about stimuli, concluded that it is futile even to attempt a general definition of the stimulus in psychology. Psychology as a whole, he says, can be equated with the problem of defining the stimulus, that is, giving a complete definition of the stimulus for a given response. To be able to do so would require that we specify "all the transformations of the environment, both external and internal, that leave the response invariant." And "for no response have we yet given a complete definition of the stimulus" in this sense (Stevens, 1951, pp. 31f.). If I understand him, what Stevens chiefly had in mind is the puzzle of constancy. He was saying that we do not know how to specify, in the chaos of literal proximal-energy stimulation, the actual cause of a given response. This is a discouraging truth.

But, unlike Stevens, I have hopes, and even some positive hypotheses to suggest. Once the contradictory assumptions about stimulation are made explicit, we can try to resolve them. For one thing we might search for an invariant component in the bewildering variety of functionally equivalent stimuli. Perhaps there is an invariant stimulus for the invariant response, after all. Many sorts of higher order variables of energy may exist, only awaiting mathematical description. They will have to be described in appropriate terms, of course, not as simple functions of frequency and amount. We must not confuse a stimulus with the elements used for its analysis. We must learn to conceive an array not as a mosaic of stimuli but as a hierarchy of forms within forms, and a flux not as a chain of stimuli but as a hierarchy of sequences within longer sequences.

Molar Stimuli. Ever since Tolman, behavior theorists have been agreeing that psychology is concerned with molar responses, not molecular ones. Accordingly we try to observe and measure what an organism is doing, not how all its muscles are contracting. With this kind of observation on the response side there should be a corresponding kind of observation on the stimulus side. We should try to discover what an organism is responding to, not what excites all the little receptors. Of course all the muscles may be contracting and all the receptors may be excited, but observation at that level is the job of the physiologists.

The same recommendation can be made for the study of perception. The gestalt theorists have demonstrated the fact of molar experience, but they did not look for molar stimuli. These may very well exist outside the laboratory and, with ingenuity, can perhaps be isolated in the laboratory. If so, we shall have a new and powerful kind of psychophysics.

This conception of molar stimuli is not wholly new. Forty-five years ago, E. B. Holt was convinced that cognition, along with behavior, was a constant function of stimulation. In this he agreed with Pavlov and Watson. But Holt emphasized that the stimulus of which cognitive behavior was a function was more abstract and more comprehensive than the stimulus of classical psychophysics. As one passes from reflexes to behavior, the effective stimulus "recedes," as Holt put it (1915, passim). By the recession of the stimulus he meant that it seems to be located far out in the environment rather than close by in the receptors. And he also meant that as cognition develops, the stimulus of which it is a function recedes more and more. Following this suggestion, one might conclude that a change in response implies a change in the stimulus to which the response is made. Learning would then involve not only an alteration of behavior but also an alteration in the effective stimulus. Presumably its molar character has gone up a stage in the hierarchy.

Potential Stimuli. Evidently the hypothesis of potential stimulation, accepted casually by some theorists, has quite radical but unrecognized impli- 
cations. We have long acknowledged the almost unlimited possibilities for new responses in learning theory; why not equally vast possibilities of new stimuli? The environment, so considered, would consist of a sort of reservoir of possible stimuli for both perception and action. Light, heat, sound, odor, gravity, and potential contacts with objects surround the individual. But this sea of energy has variables of pattern and sequence which can be registered by sense organs. They can be explored, either at one station-point or by moving around in the environment. The fields of radiating sound and odor, together with the flux of light rays reflected from surfaces, make it possible to respond to things at a distance. The changes of pattern in time serve as controlling stimuli for locomotion and manipulation. The variables and covariables and invariables of this stimulus environment are inexhaustible.

Surprisingly little has been written about potential stimuli. The sensory physiologists, of course, have read their physics and chemistry. But physical science portrays a sterile world. The variables of physics make uninteresting stimuli. Why is this true? I think it is because psychologists take for stimuli only the variables of physics as they stand in the textbooks. We have simply picked the wrong variables. It is our own fault. After all, physicists are not primarily concerned with stimuli. They have enough to do to study physical energies without worrying about stimulus energies. I think that we will have to develop the needed discipline on a do-it-yourself principle. It might be called ecological physics, with branches in optics, acoustics, dynamics, and biochemistry. We cannot wait for the physical scientists to describe and classify potential stimuli. The variables would seem to them inelegant, the mathematics would have to be improvised, and the job is not to their taste. But it is necessary. And if successful, it will provide a basis for a stimulus-response psychology, which otherwise seems to be sinking in a swamp of intervening variables.

Consider, for example, the physics (that is to say the acoustics) of speech sounds. As recently as 1951, in the Handbook of Experimental Psychology (Stevens, p. 869), the fact that a word is perceptually the same when whispered as it is when shouted was taken to prove that the physical characteristics of sound waves, frequency, intensity, and so on, cannot tell us about speech. Speech perception would require a psychological theory, not phys- ical measurement. But the invention of the sound spectrograph seems to have shown that certain higher order variables of acoustic energy are the critical constituents of speech and the stimuli for hearing it. These newly discovered invariant patterns of sound are completely physical, even if they had not previously been studied in physics. What was needed to understand the psychophysics of hearing words was not more psychology but more physics.

For another example consider the optics of an array of light. The physical variables applying to the point source and the image point do not explain the seeing of a surface. But my own work shows that the variables of an optical texture do account for the seeing of a surface, and that by manipulating textures an experimenter can produce synthetic perceptions of objects (Gibson, Purdy, \& Lawrence, 1955). Gradients, patterns, and other invariants are not part of existing geometrical optics, but they are physical facts. What was needed for a psychophysics of visual perception was not more theorizing about cues but more attention to geometrical optics.

Effective Stimuli. An effective stimulus can now be defined. It is one which arouses receptor activity, or recorded neural impulses, or sense organ ad justments, or overt responses, or verbal judgments -whichever criterion one chooses. Note that the idea of fixed innate thresholds of sensation is rejected. It always was a myth, for every psychophysical experimenter knows that the threshold obtained depends on the method used and the response criterion chosen.

In short, whether or not a potential stimulus becomes effective depends on the individual. It depends on the species to which he belongs, on the anatomy of the sense organs, the stage of maturation, the capacities for sense organ adjustment, the habits of attention, the activity in progress, and the possibilities of educating the attention of the individual. Such facts make up the field of perceptual development and perceptual learning. At the lower levels they are called facts of sensory physiology; at the higher levels, facts of attention or exploration, but they are all one problem. Animals seem to be driven to make potential stimuli effective. They use their receptor equipment, probably, in as great a variety of ways as they use their motor equipment. From this point of view, it seems to me, the senses begin to make sense. 
Stages of Specificity. Johannes Müller began the study of the way in which the modes of experience are specific to the excitations of nerve fibers. Sherrington and others showed how the excitations of fibers were generally specific to the patterns of the stimulus. Ecological physics will tell us the extent to which the proximal stimuli are specific to their sources in the world. If experience is specific to excitation, and excitation to stimulation, and stimulation to the external environment, then experience will be specific to the environment, within the limits of this chain of specificities. The first two stages have long been under investigation. The last is ripe for study. There has been a controversy over whether or not visual stimuli can specify their objects (for example, Cantril, 1950), but it can be settled, for the facts are discoverable, and arguments should await evidence.

The Informative Capacity of Molar Stimuli. If the structure and sequence of stimulus energy can be analyzed, potential stimuli can be described and arranged in a hierarchy. There will be subordinate stimuli and superordinate stimuli, of lower order and higher order. So conceived it is reasonable to assume that stimuli carry information about the terrestrial environment. That is, they specify things about objects, places, events, animals, people, and the actions of people. The rules by which they do so are to be determined, but there is at least enough evidence to warrant discarding the opposite assumption under which we have been operating for centuries-that stimuli are necessarily and intrinsically meaningless.

Natural Stimuli, Pictorial Stimuli, and Coded Stimuli. I have suggested that, instead of continuing to employ the careless analogies of our present loose terminology for stimuli-cues, clues, signals, signs, indicators, messages, inputs, and the likewe make a systematic study of the laws by which stimuli specify their sources. We need to know the laws of stimulus information. Almost certainly these will not be the laws which govern the transmission of information in human systems of communication. The natural world does not literally communicate with the sense organs. The potential physical stimuli arising from an event are not to be compared to the physical stimulus arising from the word for that event. We cannot hope to understand natural stimuli by analogy with socially coded stimuli, for that would be like putting the cart before the horse. Just this, however, is what we tend to do when we speak of the "signs" for depth perception and the "messages" of the senses. We cannot afford to speak of coded information for the sense organs when we mean stimuli, for some of these are coded and some are not.

A systematic study of the specifying power of stimuli will put the problem of meaning in perception on a new footing. It will take several forms, depending on the kinds of relations discovered. My guess is that there will be at least three, corresponding to the stimuli from things, from pictures, and from words. It is true that men, besides learning to perceive objects, also learn to apprehend things by way of perceiving pictures and words. These mediated perceptions get mixed with direct perceptions in the adult. But we shall have to disentangle them before we can have a complete theory of human perception.

\section{Conclusion}

The foregoing distinctions and assumptions seem promising to me. But I would agree that a stimulus theory cannot be established by merely asserting it. The scientific question is whether all these new kinds of stimuli exist. I suggest that we look for them in the environment and then try to bring them into the laboratory.

It is still true that the stimulus is the prime independent variable of a psychological experiment. I quote from Underwood (1957):

One may vary more than one stimulus condition in a given experiment .. . but to draw a conclusion about the influence of any given variable, that variable must have been systematically manipulated alone somewhere in the design. Nothing in analysis of variance, covariance, Latin squares, Greco-Latin squares, or Greco-Arabic-Latin squares has abrogated this basic principle (p. 35).

If Underwood is right, the secret of a good experiment is to discover the relevant stimulus before doing the experiment. The moral of my argument is that a systematic search for relevant stimuli, molar stimuli, potential stimuli, invariant stimuli, specifying stimuli, and informative stimuli will yield experiments with positive results. Perhaps the reservoir of stimuli that I have pictured is full of elegant independent variables, their simplicity obscured by physical complexity, only waiting to be discovered.

\section{REFERENCES}

Brunswik, E. Perception and the representative design of experiments. Berkeley: Univer. California Press, 1956. 
Can'rRIL, H. The "why" of man's experience. New York: Macmillan, 1950.

FReUd, S. Collected papers, London: Hogarth Press, 1949.

Grbson, J, J. \& Gibson, E. J. Continuous perspective transformations and the perception of rigid motion. $J$. exp. Psychol., 1957, 54, 129-138.

Gibson, J. J., Purdy, J, \& Lawrence, L. A method of controlling stimulation for the study of space perception: The optical tunnel. J. exp. Psychol., 1955, 50, 1-14.

Harper, R. S., \& Boring, E. G. Cues. Amer. J. Psychol., 1948, 61, 343-351.

HAYER, F. A. The sensory order. Chicago: Univer. Chicago Press, 1952.

HILGARD, E. R., \& MARQuis, D. G. Conditioning and learning. New York: Appleton-Century-Crofts, 1940.

Holt, E. B. The Freudian wish. New York: Holt, 1915.

Huld, C. L. Principles of behavior. New York: AppletonCentury-Crofts, 1943.

Jennings, H. S. Behavior of the lower organisms. New York: Columbia Univer. Press, 1906.

Koch, S. (Ed.) Psychology: A study of a science. Vol. 2. New York: McGraw-Hill, 1959.

Korfka, K. Principles of gestalt psychology. New York: Harcourt, Brace, 1935.

KöHLER, W. Gestalt psychology. New York: Liveright, 1929.
Mrther, N. E., \& Dollard, J. Social learning and imitation. New Haven: Yale Univer. Press, 1941.

Murchison, C. Handbook of general experimental psychology. Worcester: Clark Univer. Press, 1934.

Oscoob, C. E. Method and theory in experimental psychology. New York: Oxford Univer. Press, 1953.

Paviov, I. P. Conditioned reflexes. (Trans. by G. V. Anrep) London: Oxford Univer. Press, 1927.

SkINNER, B. F. The behavior of organisms. New York: Appleton-Century-Crofts, 1938.

SkINNER, B. F. Cumulative record. New York: AppletonCentury-Crofts, 1959.

SPENCE, K. W. Behavior theory and conditioning. New Haven: Yale Univer. Press, 1956.

Stevens, S. S. (Ed.) Handbook of experimental psychology. New York: Wiley, 1951.

Troland, L. T. Psychophysiology. Vol. 2. New York: Van Nostrand, 1930.

UNDERWood, B. Psychological research, New York: Appleton-Century-Crofts, 1957.

VERnON, M. D. A further study of visual perception. Cambridge: Cambridge Univer. Press, 1952.

Watson, J. B. Psychology from the standpoint of a behaviorist. Philadelphia: Lippincott, 1924.

Woodworte, R. S. Psychology. New York: Holt, 1929.

Woodworte, R. S. Dynamics of behavior. New York: Holt, 1958. 